\title{
Allogeneic stem cell transplantation for chronic myelomonocytic leukemia: a report from the Societe Francaise de Greffe de Moelle et de Therapie Cellulaire
}

Sophie Park ${ }^{1}$, Myriam Labopin ${ }^{2}$, Ibrahim Yakoub-Agha ${ }^{3}$, Jacques Delaunay ${ }^{4}$, Nathalie Dhedin ${ }^{5}$, Eric Deconinck $^{6}$, Mauricette Michallet ${ }^{7}$, Marie Robin ${ }^{8}$, Thierry De Revel ${ }^{9}$, Marc Bernard ${ }^{10}$, Norbert Vey ${ }^{11}$, Bruno Lioure $^{12}$, Simona Lapusan ${ }^{13}$, Reza Tabrizi ${ }^{14}$, Jean-Henri Bourhis ${ }^{15}$, Anne Huynh ${ }^{16}$, Yves Beguin $^{17}$, Gérard Socié ${ }^{8}$, François Dreyfus ${ }^{1}$, Pierre Fenaux ${ }^{18}$, Mohamad Mohty ${ }^{4}$

${ }^{1}$ Hematology, Hôpital Cochin, Université Paris V, Paris; ${ }^{2}$ ALWP, EBMT-Paris Office, Hôpital Saint Antoine AP-HP, Université Pierre et Marie Curie Paris 6, Paris; ${ }^{3}$ UAM Allogreffes de CSH, Lille; ${ }^{4} \mathrm{CHU}$ Nantes, Université Nantes, Nantes; ${ }^{5}$ Hematology Transplantation, Saint Louis Hospital, Paris; ${ }^{6}$ Hematology, CHU Besancon, Besancon; ${ }^{7}$ Hematology, Hopital Edouard Herriot, HCL, Universite Lyon 1, Lyon; ${ }^{8}$ Hematology-

Transplantation, Saint-Louis Hospital, Paris; ${ }^{9}$ Department of hematology, Percy hospital, Clamart; ${ }^{10}$ Service d'hématologie, Hôpital Sud de Pontchaillou, Rennes; ${ }^{11}$ Hopital Paoli-Calmettes, Marseille; ${ }^{12} \mathrm{CHU}$ Strasbourg, Strasbourg; ${ }^{13}$ Hematology, Paris; ${ }^{14} \mathrm{Hematology}, \mathrm{CHU}$ Bordeaux, Pessac; ${ }^{15}$ Hematology, Institut Gustave Roussy, Villejuif; ${ }^{16}$ Hôpital Purpan, Université Toulouse, Toulouse, France; ${ }^{17}$ University of Liège, Liège, Belgium; ${ }^{18}$ Hôpital Avicenne, AP-HP, Université Paris 13, Bobigny, France

\begin{abstract}
Objectives and methods: Chronic myelomonocytic leukemia (CMML) is a severe disease for which allogeneic stem cell transplantation (allo-SCT) remains the only potentially curative treatment. We describe a retrospective study determining prognostic factors for outcome after allo-SCT in consecutive 73 patients with CMML reported to the SFGM-TC registry between 1992 and 2009. Results: At diagnosis, median age was $53 \mathrm{yrs}$, and $36 \%$ patients had palpable splenomegaly (SPM). 48, 13, and 9 patients had good, intermediate, and poor risk karyotype, respectively, according to IPSS, 61\% patients had CMML-1, and 39\% had CMML-2. 41/31/1 cases had an HLA-identical sibling, an unrelated and haploidentical donor, respectively. 43 patients received reduced-intensity conditioning. With a median follow-up of 23 month, acute grade 2-4 and chronic GVHD developed in 21 and 25 patients, respectively. The 3-year OS, NRM (non-relapse mortality),EFS, and CIR (cumulative incidence of relapse) were 32\%, 36\%, 29\% and 35\%, respectively. OS was not influenced by the CR status, marrow blasts\% at allo-SCT, prior treatments, and cGVHD. Using multivariate analysis, year of transplant $<2004$ (YOT) $(P=0.005)$ was associated with higher NRM, YOT $<2004(P=0.04)$ and SPM at allo-SCT $(P=0.02)$ with lower EFS, and YOT $<2004$ $(P=0.03)$ and SPM at allo-SCT $(P=0.04)$ with poorer OS. Conclusions: Allogeneic stem cell transplantation is a valid treatment option for patients with CMML, and its outcome has improved with YOT > 2004. Splenomegaly seems to be a negative factor of OS and EFS in this series.
\end{abstract}

Key words allotransplantation; chronic myelomonocytic leukemia; myelodysplastic; splenomegaly

Correspondence Sophie Park, MD, PhD, Service d'hématologie Hôpital Cochin, 27 rue du Fb ST Jacques, Paris 75014, France. Tel: 01584121 31; Fax 01584120 90; e-mail: sophie.park@cch.aphp.fr

Accepted for publication 8 January 2013

doi:10.1111/ejh.12073

Chronic myelomonocytic leukemia (CMML), now classified among mixed myelodysplastic/myeloproliferative disorders (MDS/MPD), is a disease predominating in the elderly, characterized by monocytic infiltration of the bone marrow and peripheral blood, a variable degree of dysplasia, and absence of specific molecular marker (1-4). CMML is heterogeneous with regards to the importance of myeloproliferation (reflected by circulating WBC counts and monocytes and sometimes extramedullary disease), marrow dysplasia (reflected, in addition to myelodysplastic features, by a variable excess of marrow blasts and cytopenias), and progression to AML (occurring in around $30-40 \%$ of cases). The heterogeneity of disease features 
accounts for the variable overall survival (OS) that ranges from 12 months to several years in published series $(1-4)$.

Several prognostic classifications have been proposed in CMML, generally combining the 'proliferative' and 'dysplastic' aspects of the disease (5-7). Drug treatment of CMML, when poor prognostic factors are present, remains disappointing, although the hypomethylating agents decitabine and azacitidine have recently yielded some interesting results, with overall response rate around 40\% (8-11).

As in higher-risk MDS, allogeneic hematopoietic stem cell transplantation (allo-SCT) is therefore still considered as the only potentially curative approach in CMML. However, very few series of allo-SCT in CMML have been published, reporting a long-term disease-free survival and OS rates ranging between 18 and $41 \%$, and 18 and $45 \%$, respectively (12-18).

This retrospective study aimed at assessing the outcome of allo-SCT in a group of 73 consecutive CMML patients reported to the registry of the Société Française de greffe de moelle et de thérapie cellulaire (SFGM-TC).

\section{Patients and methods}

\section{Study design and patients selection}

This was a retrospective multicenter analysis. Data of all patients with CMML receiving allo-HSCT were provided by the registry of the SFGM-TC (promise). SFGM-TC is a voluntary national working group including all French transplant centers, participants of which are required once a year to report all consecutive stem cell transplantations and follow-up. The scientific council of the SFGM-TC approved this study that was conducted according to the principles of the Declaration of Helsinki.

Between 1992 and 2009, 16952 patients who had undergone allo-SCT in France were reported to the SFGM-TC registry, of whom 73 patients were diagnosed with CMML. Patients with juvenile myelomonocytic leukemia were excluded. The patient files were reviewed to confirm diagnosis of CMML, based on WHO criteria: blood monocytes $>1 \times 10^{9} / \mathrm{L}$ (with monocytes representing at least $10 \%$ of the leukocyte differential count), dysplastic features in the bone marrow, absence of eosinophilia, absence of $\mathrm{BCR}-\mathrm{ABL}$ rearrangement, and absence of $\mathrm{t}(5 ; 12)(19)$.

\section{Study endpoints and statistical analyses}

Endpoints considered were overall survival (OS), event-free survival (EFS), cumulative incidence of relapse (CIR), and non-relapse mortality (NRM).

Variables considered for their prognostic value were age (greater or less than $55 \mathrm{yrs}$, which was the median age of the population) at diagnosis, gender, presence of palpable splenomegaly at diagnosis and before transplant, $\%$ marrow blasts, white blood cell count, blood monocyte count, ANC, blood lymphocyte count, presence of blood immature granulocytes, $\mathrm{Hb}$ level, platelet count, myelodysplastic features on marrow aspirates or biopsies at diagnosis and allo-SCT, cytogenetics at diagnosis (according to IPSS classification) (20), interval between diagnosis and allo-SCT (greater or less than 12 months), prior treatment, disease status at transplantation (using FAB and WHO classification), transplant characteristics (including donor type, CMV serology, conditioning regimen), and occurrence of acute and chronic GVHD. Reduced-intensity conditioning regimen (RIC) was defined according to published criteria (21).

In the absence of consensus prognostic scoring system in CMML, three published systems at diagnosis and allo-SCT were analyzed for their prognostic value on the outcome of allo-SCT, including (i) classification in CMML-1 and CMML2 according to WHO classification, (ii) classification according to IPSS in patients with $\mathrm{WBC}<13 \times 10^{9} / \mathrm{L}$ and using prognostic factors published by the Groupe Francophone des Myélodysplasies (GFM) in CMML with WBC $>13 \times 10^{9} / \mathrm{L}$ (unfavorable factors included: palpable splenomegaly (SPM), $\mathrm{Hb}<10 \mathrm{~g} / \mathrm{dL}$, platelets $<100 \times 10^{9} / \mathrm{L}$, marrow blasts $>5 \%$, abnormal karyotype, extramedullary disease) (22), (iii) the MD Anderson classification with $\mathrm{Hb}<12 \mathrm{~g} / \mathrm{dL}$, presence of circulating immature myeloid cells, bone marrow blasts $>10 \%$, absolute lymphocyte count above $2.5 \times 10^{9} / \mathrm{L}$ (23). CIR and NRM were calculated from the date of transplant to the date of relapse or death in remission, respectively, with the other event being the competing risk (24). EFS was defined as the interval from allo-SCT to either relapse/progression or death in remission. Probabilities of OS and EFS were calculated using the Kaplan-Meier estimate; the log-rank test was used for univariate comparisons. Acute and chronic GVHD were analyzed as time-dependent variables.

Multivariate analyses were performed using Cox proportional hazards for OS and EFS and proportional subdistribution hazard regression model of fine-gray for other outcomes (25). A stepwise backward procedure was used to construct a set of independent predictors of each endpoint. All predictors achieving a $P$-value below 0.20 by univariate analysis were included in the multivariate analysis and sequentially removed if the $P$ value in the multiple model was above 0.10 . All tests were twosided. The type-I error rate was fixed at 0.05 for determination of factors associated with time to event outcomes. Statistical analyses were performed with SPSS 19 (Inc., Chicago) and R 2.13.1 software package (the $\mathrm{R}$ foundation for statistical computing - http://www.R-project.org) (25).

\section{Results}

\section{Baseline patient characteristics and treatments before transplant}

The patient population characteristics are resumed in Table 1. At diagnosis, twenty-two (30\%) patients had palpable SPM, 
Table 1 Patient characteristics at diagnosis and transplant

\begin{tabular}{|c|c|c|c|c|c|}
\hline & At diagnosis & At transplant & $\begin{array}{l}\mathrm{SPM}+\text { at } \\
\text { transplant }\end{array}$ & $\begin{array}{l}\text { SPM- at } \\
\text { transplant }\end{array}$ & $\begin{array}{l}P \text { (chi-square or } \\
\text { Mann-Whitney } \\
\text { test or Fisher's } \\
\text { test) between SPM+ } \\
\text { and SPM- }\end{array}$ \\
\hline$n=73$ & 73 & 73 & 19 & 37 & \\
\hline Age & $53(27-66)$ & $53(29-67)$ & $52(30-64)$ & $53(29-62)$ & 0.97 \\
\hline Age $>55 \mathrm{yr}$ & $28(38)$ & $22(30)$ & $8(42)$ & $14(38)$ & 0.76 \\
\hline $\begin{array}{l}\text { Disease of secondary origin or } \\
\text { transformed }\end{array}$ & $17(25)$ & $14(19)$ & $1(6)$ & $13(38)$ & 0.02 \\
\hline CMML-1 & $40(61)$ & $24(33)$ & $12(63)$ & $26(70)$ & \\
\hline CMML-2 & $25(39)$ & $26(36)$ & $5(26)$ & $3(8)$ & 0.08 \\
\hline $\mathrm{LDH}$ & $400(300-4187)$ & $496(200-4187)$ & $492(200-4187)$ & $499(333-1164)$ & 0.94 \\
\hline (\% of pts $>400$ ) & $30(42)$ & $16(22)$ & $8(67)$ & $8(57)$ & 0.7 \\
\hline Hemoglobin g/dL & $10.7(3.1-17.4)$ & $11.1(6.9-14.9)$ & $12(3.1-15.2)$ & $10.6(4.9-15.3)$ & 0.2 \\
\hline$(\%<10 \mathrm{~g} / \mathrm{dL})$ & $24(38)$ & $27(43)$ & $3(18)$ & $14(44)$ & 0.11 \\
\hline Platelets G/L & $85(3-2140)$ & $84(6-1150)$ & $76(15-900)$ & $138(3-2140)$ & 0.47 \\
\hline$(\%<100)$ & 85 & $36(60)$ & $11(61)$ & $13(42)$ & 0.2 \\
\hline White Blood cells (leukocytes) G/L & $19(3.1-820)$ & $4.8(0.1-30.8)$ & $15.9(3.1-820)$ & $23.3(4.1-75)$ & 0.51 \\
\hline$>13$ & $45(69)$ & $16(26)$ & $12(63)$ & $24(77)$ & 0.28 \\
\hline Lymphocytes G/L & $2.3(0.66-29.3)$ & $0.9(0-8.2)$ & $2.8(1.2-29.3)$ & $2.17(0.66-5.3)$ & 0.14 \\
\hline$\%<1.4 \mathrm{G} / \mathrm{L}$ & $5(13)$ & $35(66)$ & $2(14)$ & $3(17)$ & 0.47 \\
\hline Medullar blasts & $8.5(0-40)$ & $4(0-80)$ & $7(0-20)$ & $3(0-40)$ & 0.06 \\
\hline$(\%<5 \%)$ & $13(20)$ & $23(31)$ & $10(56)$ & $13(43)$ & \\
\hline Absolute monocytes in blood & $4(1-475)$ & $0.48(0.232-63.56)$ & $4.21(1.07-476)$ & $3.74(1-59)$ & 0.52 \\
\hline Absolute neutrophils in blood & $7.3(0-82)$ & $1.8(0-69)$ & $6.7(0-82)$ & $8.42(0-47)$ & 0.43 \\
\hline Myelemia (\% positive) & $43(81)$ & $30(50)$ & $15(94)$ & $20(71)$ & 0.12 \\
\hline Palpable splenomegaly & $22(30)$ & $19(26)$ & $19(100)$ & $54(100)$ & \\
\hline \multicolumn{6}{|l|}{ Karyotype risk group } \\
\hline Good & $48(69)$ & & $11(58)$ & $37(72)$ & \\
\hline Int & $13(19)$ & & $5(26)$ & $8(16)$ & \\
\hline Poor & $9(13)$ & & $3(16)$ & $6(11)$ & 0.45 \\
\hline Normal & 47 & & $11(58)$ & $26(70)$ & \\
\hline Monosomy 7 & 7 & & $3(16)$ & $4(11)$ & \\
\hline Abn 8 (tris 8) & $5(3)$ & & $5(26)$ & 7 (19) & 0.65 \\
\hline $\begin{array}{l}\text { GFM score for pts with }>13 \mathrm{G} / \mathrm{L} \text { WBC at } \\
\text { least two negative factors }\end{array}$ & $37(51)$ & $9(12)$ & $4(21)$ & $5(13)$ & 0.9 \\
\hline IPSS (low, int1, int2, high, na) & $3 / 5 / 6 / 1 / 4$ & $11 / 4 / 8 / 6 / 16$ & 0/1/4/1/8 & $10 / 3 / 4 / 3 / 8$ & NA \\
\hline Karnofsky $(\%<90)$ & $26(43)$ & $23(31)$ & $10(59)$ & $13(38)$ & 0.16 \\
\hline Infections before transplant & & $31(43)$ & $12(63)$ & $22(59)$ & 0.79 \\
\hline Delay transplantation (mo) & & $10.7(2.8-80)$ & $17(3.7-48)$ & $8.5(2.9-80)$ & 0.06 \\
\hline $\begin{array}{l}\text { Delay diagnostic transplant }>12 \text { month } \\
\mathrm{n}(\% \mathrm{pts})\end{array}$ & & $35(48)$ & $13(68 \%)$ & $11(30 \%)$ & 0.006 \\
\hline $\mathrm{AML}$ at transplant & & 6 & $1(6 \%)$ & $3(10 \%)$ & 1 \\
\hline $\mathrm{RIC}$ & & 43 & $8(42)$ & $12(33)$ & 0.52 \\
\hline Infectious complications post-transplant & & & $4(22)$ & $14(41)$ & 0.23 \\
\hline $\mathrm{CR} /$ relapse after transplant & & & $7 / 9(43 / 47)$ & $31 / 17(66 / 33)$ & cf curves \\
\hline Death due to relapse & & & $7 / 15(46 \%)$ & $12 / 29(41 \%)$ & cf curves \\
\hline Death due to HSCT & & & $8 / 15(53 \%)$ & $12 / 29(41 \%)$ & cf curves \\
\hline AML chemotherapy before transplant & & & $11(58 \%)$ & $28(76)$ & 0.17 \\
\hline
\end{tabular}

${ }^{1}$ GFM score, unfavorable factors included palpable splenomegaly (SPM), $\mathrm{Hb}<10 \mathrm{~g} / \mathrm{dL}$, Platelets $<100 \mathrm{G} / \mathrm{L}$, marrow blasts $>5 \%$, abnormal karyotype, extramedullary disease.

median WBC count was $19 \times 10^{9} / \mathrm{L}$ (range $2.8-830$ ), and $45(69 \%)$ patients had $\mathrm{WBC}>13 \times 10^{9} / \mathrm{L}$. Of the 28 patients with WBC $<13 \times 10^{9} / \mathrm{L}, 3,5,6$, and 1 patient had low-, int-1, int-2, and high-risk IPSS, respectively, while of the 45 patients with $\mathrm{WBC}>13 \times 10^{9} / \mathrm{L}, 37(82 \%)$ had at least two of the poor prognostic factors described by the GFM.

Before allo-SCT, 26 patients were treated with conventional anthracycline-cytarabine chemotherapy (CT), eight of them belonging to the good or intermediate karyotype risk 
groups. Eighteen patients received low-dose CT with hydroxyurea or VP16. Three patients received interferon, and six received a hypomethylating agent (Table 2).Thirtyone patients $(43 \%)$ were reported to have developed an infectious episode (bacterial or fungal) between diagnosis and allo-SCT, among them 11 having received high-dose chemotherapy.

Median interval from diagnosis to allo-SCT was 10.6 months (range, 2.8-80). Median year of transplantation was 2004. At time of allo-SCT, 15 patients (53\% of the patients having received CT or hypomethylating agents) were in CR (Table 2), and six had progressed to AML. The remaining 50 patients still fulfilled CMML criteria, including 24 CMML-1 and 26 CMML-2. Of the 34 patients with $\mathrm{WBC}<13 \times 10^{9} / \mathrm{L}, 4,8$, and 6 had int- 1 int-2, and higher IPSS, respectively (while 16 were not evaluable due to absence of karyotype), and 9 of the 16 patients with WBC $>13 \times 10^{9} / \mathrm{L}$ had at least two GFM poor prognostic factors (Table 1). Seventeen percent, 43\%, 23\%, and 17\% of patients had MD Anderson score of 1, 2, 3, and 4, respectively. Nineteen patients (34\%) had palpable SPM, which had developed between diagnosis and allo-SCT in nine of them. Presence of palpable SPM at allo-SCT was correlated with thrombocytopenia (median platelet number $76 \times 10^{9} / \mathrm{L}$ vs. $138 \times 10^{9} / \mathrm{L}$ in SPM + and SPM - patients, respectively, $P=0.05$ ), presence of peripheral blasts (mean 0.0083 vs. $0 \times 10^{9} / \mathrm{L}$ in SPM + and SPM - patients, respectively, $P=0.03)$, and myelemia $(78 \%$ vs. $36 \%$ in SPM+ and SPM - pts, respectively, $P=0.008)$. Patients with palpable splenomegaly tended to have a worse Karnofsky score (KS) (59\% with less than $90 \%$ KS vs. $38 \%$ for patients not having SPM at allo-SCT) and a longer interval to transplantation $(68 \%$ of patients $(\mathrm{SPM}+)$ vs. $30 \%(\mathrm{SPM}-)$ had an interval between diagnosis and allo-SCT $>12$ month compatible with more advanced disease, $P=0,06)$, and splenomegaly was not correlated with previous infections $(P=0.79)$. There was no splenectomy declared in this series.

Forty-one patients received allo-SCT from an HLAmatched related donor and 32 from a matched unrelated donor. Thirty patients $(41 \%)$ received a standard myeloablative conditioning (MAC) regimen before allo-SCT, while 43 patients $(59 \%)$ received a reduced-intensity conditioning (RIC). Graft versus host disease (GVHD) prophylaxis consisted of cyclosporine and methotrexate in 34 patients and of

Table 2 Treatment received before allogeneic stem cell transplantation

\begin{tabular}{lrrl}
\hline Treatment & $n$ & CR & $\begin{array}{l}\text { Progression } \\
\text { to AML }\end{array}$ \\
\hline Hypomethylating agent & 6 & 0 & 0 \\
AML-like chemotherapy & 26 & 15 & 5 \\
Hydroxyurea or VP16 & 18 & 0 & 0 \\
IFN & 3 & 0 & 1 \\
No treatment & 20 & 0 & 0
\end{tabular}

cyclosporine and mycophenolate mofetil in all others. Twenty-seven patients received conventional non-manipulated bone marrow as a stem cell source, and 46 patients had peripheral blood cells. Supportive care was provided according to each center's guidelines.

\section{Outcome}

With a median follow-up of 23 months (range, 1-145), grade 2-4 acute GVHD was observed in 28 patients (cumulative incidence, $41 \pm 5 \%$ at 3 months). Chronic GVHD was diagnosed in 25 patients $(35 \%)$ (limited in 15 and extensive in 10; cumulative incidence: $33 \%$ at 2 yrs). Five patients did not engraft with three of them having palpable splenomegaly at transplant.

The 2- and 3-year OS were $42 \%$ and $32 \%$, respectively (Fig. 1A). Forty-five patients had died (26 from NRM (six GvHD, four pulmonary toxicity, eight bacterial infections, four viral infections, one veino-occlusive disease, three hemorrhage events, one CNS toxicity), 19 from disease progression). The 3-year cumulative incidence of NRM was $36 \%$ (Fig. 1B). The 3-year disease-free survival was $29 \%$ (Fig. 1C). The CIR was $35 \%$ at 3 yrs (Fig. 1D).

\section{Prognostic factors}

Non-relapse mortality (NRM) was lower in female patients ( $14 \%$ vs. $41 \%, P=0.03$ ), in patients without palpable SPM at diagnosis $(22 \%$ vs. $51 \%, P=0.05)$, and in patients transplanted after 2004 (18\% vs. 46\%, $P=0.008)$. Patients who had infections ( $42 \%$ being bacterial infections, $58 \%$ viral and fungal infections) prior to transplant had a higher 2-year NRM (48\% vs. $22 \%, P=0.04)$. In multivariate analysis, $\mathrm{WBC}<13 \times 10^{9} / \mathrm{L} \quad(\mathrm{HR}=2.31 ; \quad 95 \% \quad \mathrm{CI}: \quad 1.08-5.26$; $P=0.03)$, transplant before 2004 (HR $=5.6$; 95\% CI: $1.67-$ $20 ; P=0.005)$, and infections before transplant $(\mathrm{HR}=3$; 95\% CI: $1.27-6.97 ; P=0.01)$ were significantly associated with worse NRM.

There was no influence of donor type, CMV serology in patient and in donor, conditioning regimen, $\mathrm{BM}$ vs. $\mathrm{PBC}$ on cGVHD incidence (data not shown). But in female donor to male receiver allo-SCT, there was a higher incidence of cGVHD (50\% vs. $25 \%, P=0.008)$.

Cumulative incidence of relapse (CIR), in univariate analysis, did not statistically differ by type- 2 and type-1 CMML patients at diagnosis (58\% vs. $34 \%$ at $3 \mathrm{yr}, P=0.20)$ and by cGVHD onset $(P=0.72)$, but was higher in female patients $(47 \%$ vs. $30 \%, P=0.01)$, in patients without infections before transplant ( $46 \%$ vs. $19 \%, P=0.02$ ), and tended to be higher in patients with palpable SPM at transplant ( $47 \%$ vs. $25 \%, P=0.07$ ). In multivariate analysis, female gender $(\mathrm{HR}=2.9 ; 95 \% \mathrm{CI}: 1.06-8 ; P=0,04)$ and absence of infections before transplant $(\mathrm{HR}=0.3 ; 95 \% \mathrm{CI}$ : $0.1-0.85$; $P=0.02)$ were still significantly associated with higher 

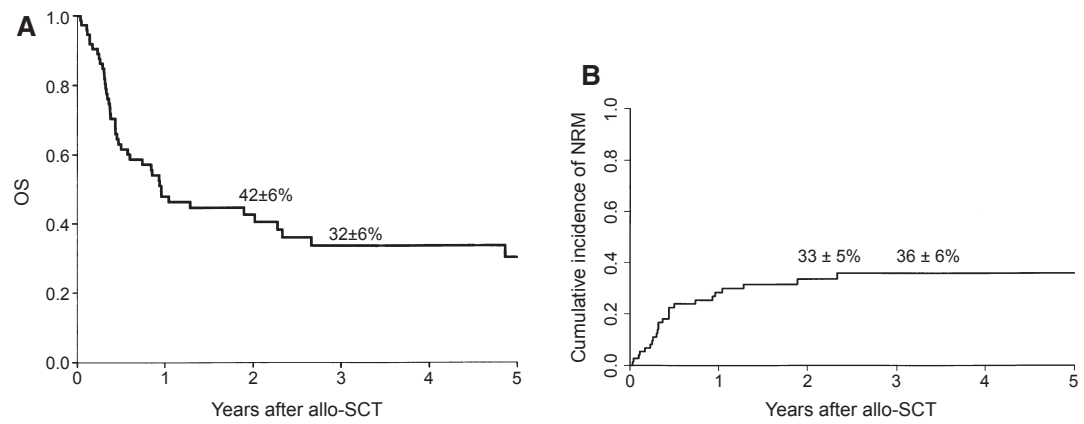

Figure 1 (A) Overall survival. (B) Cumulative incidence of non-relapse mortality (NRM). (C) Event-free survival (EFS). (D) Cumulative incidence of relapse (CIR).
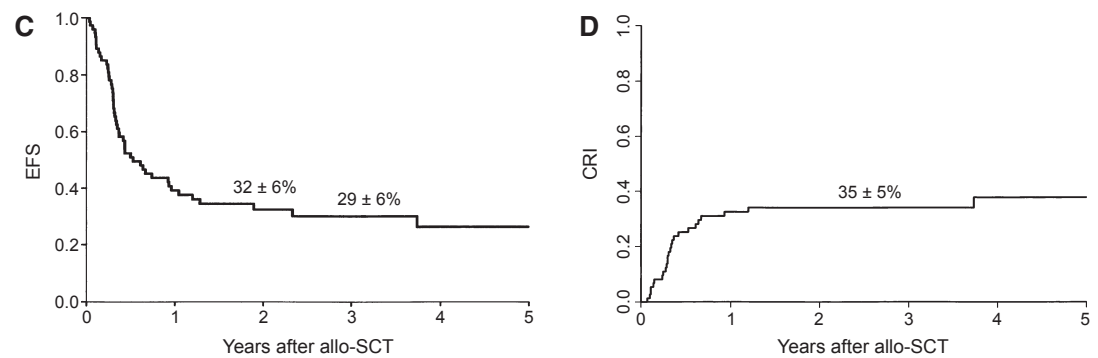

relapse incidence, while palpable SPM at transplant had only borderline significance $\quad(\mathrm{HR}=2.6 ; 95 \%$ CI: $0.93-7.3$; $P=0.07)$.

Overall survival, in univariate analysis, was not influenced by the following factors: age $>55$ yrs at diagnosis and transplant, interval from diagnosis to transplant greater than 12 months, infections before transplant, disease status at allo-SCT (CR versus others) at diagnosis and transplant, $\%$ marrow blasts, IPSS for patients with WBC $<13 \times 10^{9} / \mathrm{L}$ and GFM score for patients with WBC $>13 \times 10^{9} / \mathrm{L}, \mathrm{MD}$ Anderson score, karyotype (according to IPSS), transplant before 2004, donor type (Table 3), and conditioning (3-year OS was 33\% after MAC conditioning vs. $49 \%$ after RIC conditioning; $P=0.17$ ) (Table 3), while palpable SPM at transplant was significantly associated with poorer survival (2-year OS: $52 \%$ vs. $28 \%$ in patients with palpable SPM, $P=0.03$ ) (Fig. 2). Among the 19 patients with SPM at transplant, 15 had died: nine from HSCT-related deaths and six from relapse and disease progression. Two of the five patients who did not engraft had palpable SPM at transplant.

In multivariate analysis, the two significant unfavorable prognostic factors for OS were palpable SPM at time of transplant $(\mathrm{HR}=0.48 ; 95 \% \mathrm{CI}: 0.24-0.98 ; P=0.042)$ and transplant performed before 2004 (HR $=0.42$; 95\% CI: 0.19 $-0.91 ; P=0.03)$. The same prognostic factors were found for EFS (palpable SPM at transplant $(\mathrm{HR}=0.44 ; 95 \% \mathrm{CI}$ : $0.19-0.91 ; P=0.02)$ and transplant performed before 2004 $(\mathrm{HR}=0.46 ; 95 \%$ CI: $0.22-0.97 ; P=0.04)$ (Table 4).

\section{Discussion}

Thus far, only a few large retrospective studies of allo-SCT for CMML have been reported (Table 5). Although, all these retrospective heterogeneous studies focus on a very select population of patients with CMML who survived until the transplant and were fit enough to undergo an allogeneic transplant, they describe the outcome of the treatment considered as curative in this disease. The current series included patients transplanted for CMML in France between 1992 and 2009, 59\% of whom received RIC conditioning regimen, in a registry where clinical data such as presence of palpable splenomegaly and infections before allo-SCT are recorded, and with long-term follow-up. Three-year OS, NRM, and CIR were $32 \%, 36 \%$, and $35 \%$, respectively.

In Kroger et al.'s study published in 2002, where 50 adult cases with a median age of 44 yrs who underwent myeloablative allogeneic blood or marrow transplantation were reported, the 3-year OS and DFS were 21 and 18\%, respectively, with an estimated probability of relapse of $49 \%$ and TRM of $52 \%$ at 3 yrs (16). These results that appear poorer than the ones we report could possibly be explained by differences in patient characteristics, among them more abnormal karyotypes in the series of Kroger et al., and the myeloablative conditioning regimens that predominated before 2002. This is supported by the results of Kerbauy et al., in 43 patients with a median age of $48 \mathrm{yrs}$, of whom $50 \%$ received allo-SCT from unrelated donors (14) and who received essentially MAC regimens with busulfan- and TBIbased conditioning regimens, who reported an OS of $23 \%$, a relapse-free survival of $41 \%$ at 4 yrs and a 4 -year CIR at $23 \%$.

Recently, Eissa et al. reported, in a series of 85 patients, a 10-year PFS of $38 \%$ and 10-year relapse incidence of $27 \%$. The population in this study was quite different from ours because they were younger with more frequent unfavorable karyotype. But interestingly the outcome and 
Table 3 Univariate analyses on overall survival (OS), Event-free survival (EFS), cumulative incidence of relapse (CIR), and non-relapse mortality (NRM)

\begin{tabular}{|c|c|c|c|c|}
\hline & OS & EFS & $\mathrm{CIR}$ & NRM \\
\hline \multicolumn{5}{|c|}{ Overall results } \\
\hline $2 \mathrm{yr}$ & $42 \pm 6$ & $32 \pm 6$ & $35 \pm 5$ & $33 \pm 5$ \\
\hline $3 \mathrm{yr}$ & $32 \pm 6$ & $29 \pm 6$ & $35 \pm 6$ & $36 \pm 6$ \\
\hline \multicolumn{5}{|l|}{ Gender } \\
\hline Male & $44 \pm 8$ & $29 \pm 7$ & $30 \pm 7$ & $41 \pm 8$ \\
\hline Female & $36 \pm 10$ & $39 \pm 11$ & $47 \pm 11$ & $14 \pm 8$ \\
\hline$P$ & 0.43 & 0.71 & 0.01 & 0.03 \\
\hline \multicolumn{5}{|c|}{ At diagnosis } \\
\hline \multicolumn{5}{|c|}{ Age } \\
\hline$<55$ & $42 \pm 8$ & $32 \pm 7$ & $31 \pm 7$ & $37 \pm 7$ \\
\hline$\geq 55$ & $42 \pm 10$ & $30 \pm 10$ & $42 \pm 10$ & $28 \pm 11$ \\
\hline $\bar{P}$ & 0.65 & 0.71 & 0.28 & 0.15 \\
\hline \multicolumn{5}{|l|}{$\mathrm{Hb}(\mathrm{g} / \mathrm{dL})$} \\
\hline$<10$ & $44 \pm 11$ & $39 \pm 11$ & $33 \pm 11$ & $28 \pm 10$ \\
\hline$\geq 10$ & $47 \pm 8$ & $31 \pm 8$ & $38 \pm 8$ & $30 \pm 8$ \\
\hline$P$ & 0.54 & 0.89 & 0.88 & 0.86 \\
\hline \multicolumn{5}{|c|}{ Platelets G/L } \\
\hline$<100$ & $42 \pm 8$ & $25 \pm 7$ & $44 \pm 10$ & $31 \pm 8$ \\
\hline$\geq 100$ & $46 \pm 10$ & $44 \pm 10$ & $26 \pm 9$ & $31 \pm 10$ \\
\hline P & 0.64 & 0.03 & 0.1 & 0.1 \\
\hline \multicolumn{5}{|c|}{ WBC G/L } \\
\hline$<13$ & $39 \pm 11$ & $19 \pm 10$ & $38 \pm 12$ & $43 \pm 12$ \\
\hline$\geq 13$ & $46 \pm 8$ & $40 \pm 8$ & $33 \pm 7$ & $27 \pm 7$ \\
\hline$P$ & 0.64 & 0.06 & 0.63 & 0.2 \\
\hline \multicolumn{5}{|c|}{ Lymphocytes G/L } \\
\hline$<1.4$ & $21 \pm 8$ (only 8 pts) & $22 \pm 19$ & $17 \pm 16$ & $61 \pm 28$ \\
\hline$\geq 1.4$ & $46 \pm 9$ & $30 \pm 8$ & $45 \pm 9$ & $26 \pm 8$ \\
\hline P & 0.18 & 0.38 & 0.43 & 0.07 \\
\hline \multicolumn{5}{|c|}{ Marrow blasts (\%) } \\
\hline$\leq 10$ & $42 \pm 8$ & $29 \pm 8$ & $41 \pm 8$ & $30 \pm 8$ \\
\hline$>10$ & $47 \pm 11$ & $43 \pm 11$ & $26 \pm 9$ & $31 \pm 10$ \\
\hline$P$ & 0.49 & 0.24 & 0.26 & 0.92 \\
\hline \multicolumn{5}{|l|}{ SPM } \\
\hline No & $57 \pm 8$ & $45 \pm 8$ & $33 \pm 8$ & $22 \pm 7$ \\
\hline Yes & $15 \pm 9$ & $11 \pm 7$ & $39 \pm 11$ & $51 \pm 12$ \\
\hline$P$ & 0.009 & 0.03 & 0.6 & 0.05 \\
\hline \multicolumn{5}{|c|}{ Karyotype } \\
\hline 0 & $50 \pm 8$ & $37 \pm 7$ & $36 \pm 7$ & $27 \pm 7$ \\
\hline 1 & $50 \pm 14$ & $42 \pm 14$ & $33 \pm 14$ & $25 \pm 13$ \\
\hline 2 & $0(n=8)$ & 0 & $N A(35 \pm 18)$ & $N A(39 \pm 20)$ \\
\hline P & 0.21 & 0.31 & 0.86 & 0.37 \\
\hline \multicolumn{5}{|c|}{ Infections before transplant } \\
\hline No & $44 \pm 9$ & $32 \pm 8$ & $46 \pm 8$ & $22 \pm 7$ \\
\hline Yes & $41 \pm 9$ & $33 \pm 9$ & $19 \pm 7$ & $48 \pm 10$ \\
\hline$P$ & 0.52 & 0.69 & 0.02 & 0.04 \\
\hline \multicolumn{5}{|c|}{ Myelemia } \\
\hline No & $50 \pm 16$ & $50 \pm 16(n=10)$ & $20 \pm 13$ & $30 \pm 16$ \\
\hline Yes & $41 \pm 8$ & $28 \pm 7$ & $41 \pm 8$ & $31 \pm 8$ \\
\hline$P$ & 0.37 & 0.28 & 0.29 & 0.89 \\
\hline \multicolumn{5}{|c|}{ At transplant (tx) } \\
\hline \multicolumn{5}{|c|}{ Age } \\
\hline$<55$ & $36 \pm 8$ & $31 \pm 8$ & $30 \pm 7$ & $39 \pm 8$ \\
\hline$\geq 55$ & $47 \pm 10$ & $31 \pm 9$ & $40 \pm 9$ & $29 \pm 10$ \\
\hline$P$ & 0.19 & 0.41 & 0.49 & 0.16 \\
\hline
\end{tabular}


Table 3 (continued)

\begin{tabular}{|c|c|c|c|c|}
\hline & OS & EFS & $\mathrm{CIR}$ & NRM \\
\hline \multicolumn{5}{|c|}{ Year of transplant } \\
\hline$\leq 2004$ & $31 \pm 8$ & $19 \pm 6$ & $35 \pm 8$ & $46 \pm 8$ \\
\hline$>2004$ & $53 \pm 10$ & $47 \pm 10$ & $34 \pm 9$ & $18 \pm 8$ \\
\hline$P$ & 0.19 & 0.016 & 0.92 & 0.008 \\
\hline \multicolumn{5}{|c|}{ Blasts in BM } \\
\hline$\leq 10 \%$ & $44 \pm 7$ & $33 \pm 7$ & $31 \pm 7$ & $35 \pm 7$ \\
\hline$>10 \%$ & $27 \pm 12$ & $21 \pm 11$ & $50 \pm 14$ & $29 \pm 13$ \\
\hline$P$ & 0.47 & 0.5 & 0.23 & 0.52 \\
\hline \multicolumn{5}{|l|}{ SPM at tx } \\
\hline No & $52 \pm 9$ & $48 \pm 9$ & $25 \pm 8$ & $28 \pm 8$ \\
\hline Yes & $28 \pm 11$ & $16 \pm 8$ & $47 \pm 12$ & $37 \pm 12$ \\
\hline$P$ & 0.03 & 0.01 & 0.07 & 0.58 \\
\hline \multicolumn{5}{|c|}{ Conditioning regimen } \\
\hline MAC & $33 \pm 9$ & $30 \pm 8$ & $30 \pm 9$ & $40 \pm 9$ \\
\hline $\mathrm{RIC}$ & $49 \pm 8$ & $34 \pm 8$ & $39 \pm 8$ & $27 \pm 7$ \\
\hline P & 0.17 & 0.45 & 0.71 & 0.22 \\
\hline \multicolumn{5}{|c|}{ Status at $t x$} \\
\hline No CR & $42 \pm 9$ & $33 \pm 8$ & $38 \pm 8$ & $29 \pm 8$ \\
\hline $\mathrm{CR}$ & $43 \pm 11$ & $41 \pm 10$ & $25 \pm 9$ & $40 \pm 11$ \\
\hline P & 0.89 & 0.55 & 0.41 & 0.22 \\
\hline \multicolumn{5}{|c|}{ Donor type } \\
\hline HLA id & $42 \pm 8$ & $25 \pm 7$ & $36 \pm 8$ & $39 \pm 8$ \\
\hline Other & $40 \pm 10$ & $40 \pm 10$ & $34 \pm 9$ & $26 \pm 9$ \\
\hline$P$ & 0.78 & 0.55 & 0.83 & 0.24 \\
\hline \multicolumn{5}{|c|}{ Interval from diagnosis to transplant } \\
\hline$<11$ & $42 \pm 9$ & $38 \pm 8$ & $35 \pm 8$ & $27 \pm 8$ \\
\hline$>11$ & $41 \pm 9$ & $26 \pm 8$ & $35 \pm 8$ & $39 \pm 9$ \\
\hline$P$ & 0.51 & 0.56 & 0.79 & 0.4 \\
\hline
\end{tabular}

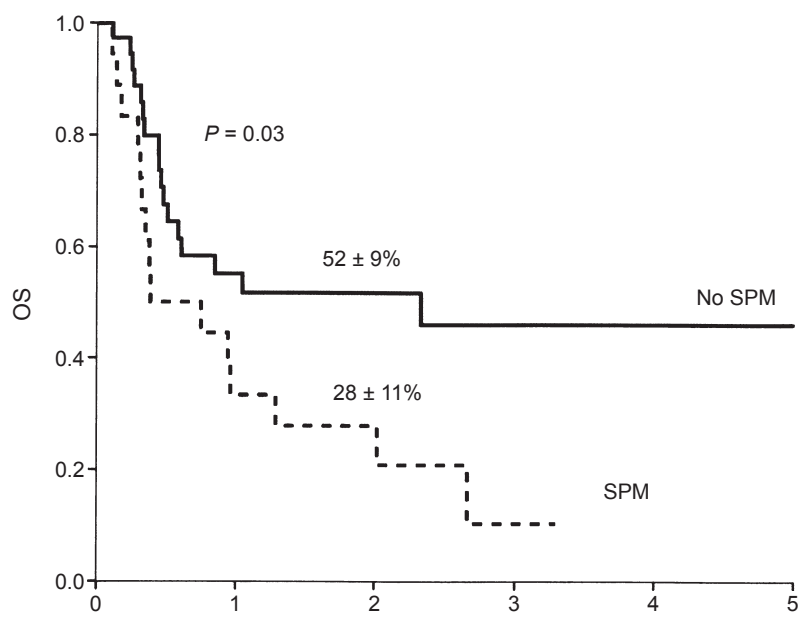

Figure 2 Overall survival according to presence of palpable splenomegaly at allogeneic stem cell transplantation.

prognostic factors of survival are closely related, possibly due to the predominant use of RIC conditioning regimens as in our study (13).

Three-year OS was 33\% after MAC conditioning vs. $49 \%$ after RIC in the present work, a difference that was, how-
Table 4 Multivariate analysis. All variables with $P<0.15$ by stepwise selection

\begin{tabular}{lllll}
\hline & & \multicolumn{3}{c}{$95.0 \% \mathrm{Cl}$} \\
\cline { 5 - 5 } & $P$ & HR & inferior & superior \\
\hline OS & & & & \\
$\quad$ Year of transplant $\leq 2004$ & 0.028 & 0.42 & 0.19 & 0.91 \\
$\quad$ SPM at transplant & 0.042 & 0.48 & 0.24 & 0.98 \\
EFS & & & & \\
$\quad$ Year of transplant $\leq 2004$ & 0.041 & 0.46 & 0.22 & 0.97 \\
$\quad$ SPM at transplant & 0.02 & 0.44 & 0.22 & 0.88 \\
CIR & & & & \\
$\quad$ Female versus male & 0.04 & 2.9 & 1.06 & 8 \\
$\quad$ SPM at transplant & 0.07 & 2.6 & 0.93 & 7.3 \\
$\quad$ No Infection at diagnosis & 0.024 & 3.3 & 1.18 & 10 \\
$\quad$ NRM & & & & \\
$\quad$ Infection at diagnosis & 0.06 & 2.18 & 0.97 & 4.9 \\
$\quad$ Year of transplant $\leq 2004$ & 0.007 & 3.85 & 1.45 & 3.85 \\
\hline
\end{tabular}

ever, not significant, and the use of a RIC regimen did not significantly reduce the incidence of NRM. But the year of transplant after 2004 influenced positively OS and EFS, with more than $70 \%$ of RIC after 2004. Thus far, studies 
Table 5 Review of literature of allo-SCT in CMML

\begin{tabular}{|c|c|c|c|c|c|c|c|c|}
\hline Paper & $n$ & DS & EFS & TRM & $R L$ & aGVHD & $\begin{array}{l}\text { Conditionin } \mathrm{g} \\
\text { regimens }\end{array}$ & $\begin{array}{l}\text { Predictive factors } \\
\text { of survival }\end{array}$ \\
\hline Kroger, BJH 2002 (13) & 50 & $21(5 \mathrm{yr})$ & 18 (5 yr) & 52 & 49 & $\begin{array}{l}35 \% \text { grade } \mathrm{II} 20 \% \\
\text { grade III-IV }\end{array}$ & MAC & $\begin{array}{l}\text { Absent but } \\
\text { tendency for } \\
\text { aGVHD }\end{array}$ \\
\hline Elliott, BMT 2006 (17) & 17 & $18(3 \mathrm{yr})$ & 18 (3 yr) & $\begin{array}{l}41 \text { (6 month) } \\
11(100 \mathrm{~d})\end{array}$ & 41 (6 month) & $75 \%$ gll-II 37\% gll|-IV & MAC & Absent \\
\hline Mittal, BMT 2004 (13) & 8 & 37 & 37 & 12 & 62 & 25 cGVHD (37\%) & MAC and RIC & Absent \\
\hline Kerbauy, BBMT 2005 (11) & 43 & 23 & 41 & 34 & 23 & Na cGVHD (54\%) & MAC & Comorbidities \\
\hline Ochem. BMT 2009 (28) & 12 & 75 (3 yr) & 43 (3 yr) & $25(100 \mathrm{~d})$ & 17 & $\begin{array}{l}46 \% \text { g II-IV, } 23 \% \\
\text { g III-IV }\end{array}$ & $\begin{array}{l}\text { MAC and RIC } \\
(n=5)\end{array}$ & Absent \\
\hline $\begin{array}{l}\text { Krishnamurthy. BMT } \\
2010 \text { (15) }\end{array}$ & 18 & 31 & 30 & 31 & 47 & 44 & $\mathrm{RIC}$ & Cytogenetics CR \\
\hline Eissa, Biol BMT 2011 (13) & 85 & & $38(10 \mathrm{yr})$ & & 27 (10 yr) & $\begin{array}{l}72 \% \text { gll-IV } 26 \% \\
\text { cGVHD }\end{array}$ & MAC and RIC & $\begin{array}{l}\text { pre-HCT } \\
\text { hematocrit, } \\
\text { cytogenetics, age, } \\
\text { HCT comorbidity } \\
\text { index }\end{array}$ \\
\hline
\end{tabular}

$\mathrm{HCT}$, hematoloietic cell transplantation; MAC, myeloablative conditioning regimen; RIC, reduced intensity conditioning regimen; c GVHD, chronic GVHD; gll-III aGVHD, grade II-III acute GVHD; TRM, transplant related mortality.

specifically addressing the use of RIC allo-SCT for CMML have included only a limited number of cases, and follow-up was short (26). In the report from Ocheni et al. (26), 12 patients were included with a follow-up of 26 months with a high 3-year TRM of $25 \%$, severe acute GVHD being a major cause of TRM.

In the current study, palpable SPM at transplant was significantly associated with poorer OS, a finding has not been previously made in adult CMML undergoing allo-SCT, to our knowledge. In addition, palpable SPM was also a predictive factor for poorer OS in multivariate analysis. The presence of splenomegaly in this disease, however, could be a mere surrogate of other negative features related to the biology of disease (proliferative form of CMML, thrombocytopenia, presence of peripheral blasts cells in $\mathrm{PB}$, adverse cytogenetics, etc.), a longer disease evolution, or even hostrelated features such as performance status, and not an adverse prognostic factor 'per se'. Palpable splenomegaly probably reflects more advanced disease although it did not increase CIR. Alternatively, it could reflect a general status of the patient who tended to have a poorer Karnofsky score. Sample size of current series and interaction with many other factors might preclude a robust multivariate analysis. There was no splenectomy declared in this series, with the limitation of a retrospective registry data, but there was no consensus in the centers on the issue of splenectomy before allogeneic transplantation.

We found no prognostic impact, on OS, of the scoring systems that have demonstrated an impact on survival in CMML outside of the transplant setting, including the classification in CMML-1 and CMML-2, the MD Anderson score, the IPSS, and the GFM score described above. In Kerbauy's series (14), the IPSS and the MD Anderson score also did not correlate with outcomes. Other previously published series of CMML found no prognostic factors for OS after alloSCT $(14,16)$.

In Eissa's study, mortality was negatively correlated with pretransplant hematocrit and increased with high-risk cytogenetics, higher number of comorbidities, and increased age (13). In Kerbauy's series, patients with higher HCT-specific comorbidity index had worse overall survival than patients with lower score (14). We could not evaluate those parameters, as HCT-specific comorbidity index data are not available in the SFGM-TC registry.

In the present report, the CR status at allo-SCT did not influence outcome, contrary to what was reported in a previous series (12). Thus, it remains unclear whether reducing marrow blasts by chemotherapy (27) before allo-SCT is useful in CMML. It may even be deleterious to administer several cycles of chemotherapy to these patients, as the occurrence of infections before allo-SCT could have a negative impact on NRM. Patients with infections before allo-SCT tended to have a poorer survival and higher NRM, a finding not previously reported in studies of allotransplant in CMML (12-17). The hypomethylating agents azacitidine or decitabine may represent novel alternatives for cytoreduction prior to allo-SCT $(8,28)$, allowing patients to reach transplant without increased chemotherapy-related toxicities, although they need prospective evaluation in that context (29).

By contrast with a previous study showing an impressive 3 -year DFS of $65 \%$ in 18 patients with favorable cytogenetics (15), karyotype did not influence OS in our series and in different other series (13, 15-17). But Such et al. (30) had described a new prognostic system for CMML with three 
subgroups of karyotypes (low-risk group: normal, -Y, highrisk group: -7 or complex karyotypes, and intermediate-risk group: other). There was an impact of karyotype classified as such on OS in our series with significant differences between low- and intermediate- vs. high-risk cytogenetics groups (data not shown). This warrants further confirmation on larger series. In the future, it is likely that analysis of somatic gene mutations (including ASXL1, TET2, AML1, N-RAS, EZH2, IDH1/2, and spliceosome gene mutations) found in more than $50 \%$ of patients with CMML may help further refine prognosis analysis in CMML (22, 31-32).

In conclusion, findings from the current analysis suggest that allo-SCT is a valid treatment option for patients with CMML eligible to such therapy. Palpable SPM at time of transplantation is a significant independent negative prognostic factor for OS, while NRM may be influenced by the occurrence of infections prior to transplant.

Further improvements in allotransplantation procedures in CMML should improve outcome of these patients.

\section{Acknowledgements}

We thank Nicole Raus, the SFGM-TC data manager and the GFM.

\section{Conflict of interest}

There is no conflict of interest.

\section{References}

1. Baudard M, Delmer A, Zittoun R. Chronic myelomonocytic leukemia in adults. Pathol Biol (Paris) 1997;45:605-11.

2. Beran M, Shen Y, Onida F, Wen S, Kantarjian H, Estey E. Prognostic significance of monocytosis in patients with myeloproliferative disorders. Leuk Lymphoma 2006;47:417-23.

3. Elliott MA. Chronic neutrophilic leukemia and chronic myelomonocytic leukemia: WHO defined. Best Pract Res Clin Haematol 2006;19:571-93.

4. Onida F, Beran M. Chronic myelomonocytic leukemia: myeloproliferative variant. Curr Hematol Rep 2004;3:218-26.

5. Fenaux P, Beuscart R, Lai JL, Jouet JP, Bauters F. Prognostic factors in adult chronic myelomonocytic leukemia: an analysis of 107 cases. J Clin Oncol 1988;6:1417-24.

6. Germing U, Kundgen A, Gattermann N. Risk assessment in chronic myelomonocytic leukemia (CMML). Leuk Lymphoma 2004;45:1311-8.

7. Wattel E, Guerci A, Hecquet B, et al. A randomized trial of hydroxyurea versus VP16 in adult chronic myelomonocytic leukemia. Groupe Francais des Myelodysplasies and European CMML Group. Blood 1996;88:2480-7.

8. Lubbert M, Suciu S, Baila L, et al. Low-dose decitabine versus best supportive care in elderly patients with intermediateor high-risk myelodysplastic syndrome (MDS) ineligible for intensive chemotherapy: final results of the randomized phase III study of the European Organisation for Research and Treatment of Cancer Leukemia Group and the German MDS Study Group. J Clin Oncol 2011;29:1987-96.

9. Costa R, Abdulhaq H, Haq B, Shadduck RK, Latsko J, Zenati M, Atem FD, Rossetti JM, Sahovic EA, Lister J. Activity of azacitidine in chronic myelomonocytic leukemia. Cancer 2011;117:2690-6.

10. Scott BL, Ramakrishnan A, Storer B, Becker PS, Petersdorf $\mathrm{S}$, Estey EH, Deeg HJ. Prolonged responses in patients with MDS and CMML treated with azacitidine and etanercept. $\mathrm{Br}$ J Haematol 2010;148:944-7.

11. Wijermans PW, Ruter B, Baer MR, Slack JL, Saba HI, Lubbert M. Efficacy of decitabine in the treatment of patients with chronic myelomonocytic leukemia (CMML). Leuk Res 2008;32:587-91.

12. Zang DY, Deeg HJ, Gooley T, Anderson JE, Anasetti C, Sanders J, Myerson D, Storb R, Appelbaum F. Treatment of chronic myelomonocytic leukaemia by allogeneic marrow transplantation. Br J Haematol 2000;110:217-22.

13. Eissa H, Gooley TA, Sorror ML, et al. Allogeneic hematopoietic cell transplantation for chronic myelomonocytic leukemia: relapse-free survival is determined by karyotype and comorbidities. Biol Blood Marrow Transplant 2011;17:908-15.

14. Kerbauy DM, Chyou F, Gooley T, Sorror ML, Scott B, Pagel JM, Myerson D, Appelbaum FR, Storb R, Deeg HJ. Allogeneic hematopoietic cell transplantation for chronic myelomonocytic leukemia. Biol Blood Marrow Transplant 2005;11:713-20.

15. Krishnamurthy P, Lim ZY, Nagi W, Kenyon M, Mijovic A, Ireland R, Marsh J, Ho AY, Mufti GJ, Pagliuca A. Allogeneic haematopoietic SCT for chronic myelomonocytic leukaemia: a single-centre experience. Bone Marrow Transplant 2010;45:1502-7.

16. Kroger N, Zabelina T, Guardiola P, Runde V, Sierra J, Van Biezen A, Niederwieser D, Zander AR, De Witte T. Allogeneic stem cell transplantation of adult chronic myelomonocytic leukaemia. A report on behalf of the Chronic Leukaemia Working Party of the European Group for Blood and Marrow Transplantation (EBMT). Br J Haematol 2002;118:67-73.

17. Elliott MA, Tefferi A, Hogan WJ, et al. Allogeneic stem cell transplantation and donor lymphocyte infusions for chronic myelomonocytic leukemia. Bone Marrow Transplant 2006;37:1003-8.

18. Mittal P, Saliba RM, Giralt SA, Shahjahan M, Cohen AI, Karandish S, Onida F, Beran M, Champlin RE, de Lima M. Allogeneic transplantation: a therapeutic option for myelofibrosis, chronic myelomonocytic leukemia and Philadelphianegative/BCR-ABL-negative chronic myelogenous leukemia. Bone Marrow Transplant 2004;33:1005-9.

19. Vardiman JW, Thiele J, Arber DA, et al. The 2008 revision of the World Health Organization (WHO) classification of myeloid neoplasms and acute leukemia: rationale and important changes. Blood 2009;114:937-51.

20. Greenberg P, Cox C, LeBeau MM, et al. International scoring system for evaluating prognosis in myelodysplastic syndromes. Blood 1997;89:2079-88. 
21. Bacigalupo A, Ballen K, Rizzo D, et al. Defining the intensity of conditioning regimens: working definitions. Biol Blood Marrow Transplant 2009;15:1628-33.

22. Braun T, Itzykson R, Renneville A, et al. Molecular predictors of response to decitabine in advanced chronic myelomonocytic leukemia: a phase II trial. Blood 2011;118:3824-31.

23. Onida F, Kantarjian HM, Smith TL, Ball G, Keating MJ, Estey EH, Glassman AB, Albitar M, Kwari MI, Beran M. Prognostic factors and scoring systems in chronic myelomonocytic leukemia: a retrospective analysis of 213 patients. Blood 2002;99:840-9.

24. Gooley TA, Leisenring W, Crowley J, Storer BE. Estimation of failure probabilities in the presence of competing risks: new representations of old estimators. Stat Med 1999;18:695-706.

25. Scrucca L, Santucci A, Aversa F. Competing risk analysis using R: an easy guide for clinicians. Bone Marrow Transplant 2007;40:381-7.

26. Ocheni S, Kroger N, Zabelina T, Zander AR, Bacher U. Outcome of allo-SCT for chronic myelomonocytic leukemia. Bone Marrow Transplant 2009;43:659-61.

27. Field T, Perkins J, Huang Y, et al. 5-Azacitidine for myelodysplasia before allogeneic hematopoietic cell transplantation. Bone Marrow Transplant 2010;45:255-60.
28. Lubbert M, Ruter BH, Claus R, et al. A multicenter phase II trial of decitabine as first-line treatment for older patients with acute myeloid leukemia judged unfit for induction chemotherapy. Haematologica 2012;97:393-401.

29. Droin N, Jacquel A, Hendra JB, et al. Alpha-defensins secreted by dysplastic granulocytes inhibit the differentiation of monocytes in chronic myelomonocytic leukemia. Blood 2010;115:78-88.

30. Such E, Cervera J, Costa D, et al. Cytogenetic risk stratification in chronic myelomonocytic leukemia. Haematologica 2011;96:375-83. doi:10.3324/haematol.2010.030957. Epub 2010 Nov 25.

31. Jankowska AM, Makishima H, Tiu RV, et al. Mutational spectrum analysis of chronic myelomonocytic leukemia includes genes associated with epigenetic regulation: UTX, EZH2, and DNMT3A. Blood 2011;118:3932-41.

32. Gelsi-Boyer V, Trouplin V, Roquain J, et al. ASXL1 mutation is associated with poor prognosis and acute transformation in chronic myelomonocytic leukaemia. Br J Haematol 2010;151:365-75. 